\title{
Story of a Video Game Workshop: "Ico", an Interactive Fairy Tale for Children Less Interaction
}

\author{
Michael Stora \\ Clinical Psychologist, Co-creator of the "Observatory of Digital World in Human Studies", \\ author of "Guérir par le jeu par les jeux vidéo, une nouvelle approche thérapeutique" \\ Collection les Presses de la renaissance, Paris, 2005
}

\begin{abstract}
The Since several years, I use the video game as a therapeutic object. This new mediation seems pertinent for children that we qualified "limit". Those children are more in the game in the gambling sense, than in the Winnicot's play. The video game is relevant in a clinic sense for two reasons essential. The first reason is that mediation is in picture and children and adolescents have an intimate attachment to these who have the power to do emerge affects and words that in generally are repressed. The second reason is this meeting between narcissism pathology and the use of video game as a place of virtue's passage in act. The acting becomes symbolic and the conflict showed by the narration of the video game is in a dynamic point between drive and narcissism.
\end{abstract}

The Author. After my education as a film-maker, I became a clinical psychologist, and, ever since I am constantly preoccupied by the unconscious links between human being and images. In 2000, I created a Partnership Association named: "Observatory of Digital World in Human Studies", for developing new theories on Interactivity, this new connection to images. I, moreover, used video games as a therapeutic tool for children with violent behaviour troubles. In 2008, I launched the Company "Implicit Game" with the aim of creating video games for healing. I am currently working on a project of an on-line game for youngs adutls and teen agers suffering of cancer. 